\title{
ALGUMAS PROPRIEDADES FÍSICAS E HÍDRICAS DE TRÊS SOLOS NA CHAPADA DO APODI, RN, CULTIVADOS COM MELÃO ${ }^{(1)}$
}

\author{
Jaedson Claudio Anunciato Mota ${ }^{(2)}$, Raimundo Nonato de Assis \\ Júnior $^{(3)}$, Joaquim Amaro Filho ${ }^{(4)}$ \& Paulo Leonel Libardi ${ }^{(5)}$
}

\begin{abstract}
RESUMO
Este trabalho teve o objetivo de caracterizar os principais solos explorados com a cultura do melão na Chapada do Apodi - RN, no qual se refere aos aspectos físicos, visando fornecer subsídios para adequado manejo da cultura e do solo. Foram estudados, em setembro de 2003, três solos: Cambissolo Háplico Ta eutrófico típico - CXve (Typic Haplocambids), Latossolo Vermelho-Amarelo eutrófico típico - LVAe (Typic Eutrotorrox) e Argissolo Vermelho distrófico arênico - PVd (Arenic Kandiustults). Uma análise geral dos atributos físicos revelou que os perfis apresentam densidade acima dos valores normais para solos afins, com maiores agravantes para os perfis 2 (LVAe) e 3 (PVd), que se refletem na porosidade total e no desbalanço da proporção macro:microporosidade; o manejo da irrigação dos três solos deve ser diferenciado, obedecendo às relações macro:microporosidade; a estabilidade de agregados em água é relativamente boa em todos os perfis; a capacidade de água disponível para a profundidade $d e$ efetiva para as raízes do meloeiro) é decrescente do perfil 1 (CXve) para o perfil 3 (PVd); o uso e manejo do solo diminuiu o grau de floculação dos horizontes superficiais dos perfis 1 (CXve) e 2 (LVAe); e, considerando o índice de plasticidade, o risco de degradação pelo uso de máquinas e implementos é acentuado no perfil 1 (CXve) e baixo nos perfis 2 (LVAe) e 3 (PVd).
\end{abstract}

Termos de indexação: densidade do solo, estrutura, porosidade.

\footnotetext{
${ }^{(1)}$ Recebido para publicação em março de 2007 e aprovado em agosto de 2007.

${ }^{(2)}$ Doutorando da Escola Superior de Agricultura Luiz de Queiroz - ESALQ/USP. Av. Pádua Dias 11, CEP 13418-900 Piracicaba (SP). Bolsista do CNPq de 4/2002 a 2/2004. E-mail: jaedsonmota@yahoo.com.br

${ }^{(3)}$ Professor Associado do Departamento de Ciências do Solo, Universidade Federal do Ceará - UFC. CEP 60021-970 Fortaleza (CE). E-mail: assisjr@ufc.br

(4) Professor do Departamento de Ciências Ambientais, Universidade Federal Rural do Semi-Árido - UFERSA. Caixa Postal 137, CEP 59625-970 Mossoró (RN). E-mail: jamaro@ufersa.edu.br

${ }^{(5)}$ Professor Titular da Escola Superior de Agricultura Luiz de Queiroz - ESALQ/USP. Bolsista do CNPq. E-mail: pllibard@carpa.ciagri.usp.br
} 


\title{
SUMMARY: SOME PHYSICS AND HYDRAULICS PROPERTIES OF THREE SOILS IN THE APODI TABLELAND, RN, CULTIVATED WITH MUSK MELON
}

\begin{abstract}
This study had the objective of characterizing the main soil types cultivated with melon, based on physical features, in the Apodi Tableland, state of Rio Grande do Norte, to provide basic information for an adequate soil and crop management. Three soil types were studied, in September 2003: Cambissolo Háplico Ta eutrófico típico - CXve (Typic Haplocambids), Latossolo Vermelho-Amarelo eutrófico típico - LVAe (Typic Eutrotorrox) e Argissolo Vermelho distrófico arênico - PVd (Arenic Kandiustults). A general analysis of the soil physical attributes in the profiles revealed bulk density values above the normal values for such soils, while higher values were found for the profiles $2(L V A e)$ and $3(P V d)$, expressed in the total porosity and the imbalance of the ratio of macro:microporosity. The irrigation management of the three soils must be differentiated, according to the ratio of macro: microporosity. The soil aggregate stability in water was satisfactory in all profiles studied; the capacity of available water at a depth of $30 \mathrm{~cm}$ (real depth for musk melon roots) decreased from profile $1(C X v e)$ to profile $3(P V d)$. The soil use and management decreased the flocculation degree of the surface horizons of the profiles 1 (CXve) and 2 ( $L V A e)$ and, considering the plasticity index, the degradation risk for the use of machines and implements is accentuated in profile 1 (CXVe) and low in the profiles 2 (LVAe) and 3 $(P V d)$.
\end{abstract}

Index terms: bulk density, porosity, structure.

\section{INTRODUÇÃO}

A agricultura irrigada tornou-se uma realidade no semi-árido brasileiro. Aos poucos, a condição de importador da maioria dos produtos agrícolas demandados está sendo substituída pela produção em alta escala, capaz de não somente abastecer o mercado interno, mas também de fazer chegar à mesa mais distantes deste planeta os chamados produtos hortifrutigranjeiros, como prova do potencial que a região apresenta. Quanto ao Rio Grande do Norte, o Estado tem na fruticultura um dos setores que mais contribuíram para as mudanças na estrutura econômica regional. Particularmente, a cultura do melão tem despontado em relação às demais frutas produzidas, destacando-se de modo significativo dentre as culturas exploradas temporariamente.

O Rio Grande do Norte apresenta um conjunto de solos cujas potencialidades não são ainda tão bem conhecidas. Um estudo realizado por Jacomine et al. (1971) é uma das raras fontes disponíveis para avaliação dos solos do Estado, uma importante contribuição ao conhecimento dos solos da região, dada a qualidade e a magnitude das informações. Entretanto, por se tratar de um levantamento em nível exploratórioreconhecimento, as informações são muito generalizadas e heterogêneas, haja vista, segundo Vieira (1988), estudos desse nível se prestarem para avaliar qualitativamente as possibilidades edáficas, bem como identificar áreas potencialmente capazes de gerar desenvolvimento, em antecipação a um levantamento com riquezas de detalhes.
Conforme Amaro Filho (1991), a variabilidade de solos da região e suas limitações quanto à mecanização, fertilidade, salinidade, drenagem e profundidade efetiva fazem com que a exploração dessas terras seja variável, necessitando, portanto, de estudos localizados para cada tipo de solo.

Por atributos físicos entende-se um conjunto de caracteres que delineiam o comportamento do solo como um todo. Dentre eles, merecem destaque a granulometria, densidade de partícula, densidade do solo, porosidade (total, macro e micro), retenção de água, estrutura e consistência (limites de Atterberg).

Thurler (1989) ressalta a importância da granulometria sobre propriedades do solo, como aeração e retenção de água. O autor, estudando relações entre propriedades físicas do solo, concluiu que a partir da granulometria é possível estimar a porosidade de distintos solos no Estado de São Paulo.

Avaliando curvas características de umidade do solo, Buckman \& Brady (1989) verificaram que elas variam especificamente com a granulometria. As maiores retenções de água ao longo de toda a faixa de energia estão associadas aos solos com frações granulométricas mais finas, os quais apresentam maior percentagem de material coloidal, maior espaço poroso e superfície específica para adsorção bem maior, quando comparados aos solos de granulometria mais grosseira.

A densidade de partículas tem valor considerável, uma vez que é requisitada na maioria das expressões matemáticas em que o volume ou peso da amostra do 
solo estão sendo considerados (Rando, 1981). Desse modo, inter-relações da porosidade, densidade do solo e taxa de sedimentação das partículas em meio fluido dependem da densidade destas. A densidade de partículas é um atributo estático, considerando-se que mudanças só seriam perceptíveis em um tempo bastante considerável. Por sua vez, a densidade do solo é um atributo que varia com o tempo (por processos naturais de adensamento) e, ou, com práticas de manejo.

De acordo com Correchel (1998), o grau e a intensidade de mobilização do solo influenciam os valores de densidade do solo. Estudando a variação da densidade do solo em relação à linha de plantio, em dois sistemas de preparo do solo (convencional e plantio direto), o autor observou que a distribuição da densidade do solo no campo é influenciada pela posição relativa à linha de cultivo e que varia de forma sistemática com a posição linha e entrelinha nos dois sistemas de manejo.

Avaliando as alterações que o manejo do solo provoca nas propriedades físicas de um Latossolo Vermelho, Klein \& Libardi (2002) concluíram que o manejo do solo irrigado, comparado ao solo de mata e sequeiro, aumentou a densidade do solo até a profundidade de $40 \mathrm{~cm}$, alterando, conseqüentemente, a distribuição do diâmetro dos poros e a porosidade de aeração.

Vários estudos têm sido realizados visando estabelecer a relação da porosidade com a produção vegetal. Baver \& Farnsworth (1940), ao estudarem a relação entre a macroporosidade e a produção de beterraba-açucareira, concluíram que perdas de produtividade chegavam a $50 \%$ quando a porosidade não-capilar atingia os $2 \%$. Concluíram também que com macroporosidade entre 7 e $10 \%$ há produção de bons tipos de beterraba, com elevado conteúdo de açúcar. Especificamente para cana-de-açúcar, Robinson (1964), controlando o volume de ar do solo pelo lençol freático, concluiu que a macroporosidade média de $11 \%$ permitiu funcionamento normal das raízes da cultura. Para o cultivo de milho há exigências de valores mínimos de macroporosidade de 12 a $15 \%$, abaixo dos quais, por dois a três dias, o metabolismo é acentuadamente alterado. Quanto ao tomateiro, apenas valores menores que $5 \%$ são críticos para o seu crescimento e desenvolvimento (Reichardt, 1990).

Em se tratando da relação solo-água, Buckman \& Brady (1989) ressaltam duas justificativas que evidenciam sua importância. Primeiro, há necessidade de grande quantidade de água para atender à evapotranspiração do sistema solo-planta. Depois, a água, por ser solvente universal, junto com os nutrientes dissolvidos, compõe a solução do solo.

A energia medida em termos de potencial é variável, uma vez que o comportamento da água no solo é complexo em virtude da heterogeneidade que um perfil pode apresentar, destacando-se a densidade do solo, o tamanho, a forma e a disposição de vazios, a textura, a estrutura, a superfície específica, a quantidade de material orgânico, a natureza dos argilominerais, o manejo e outros (Jorge, 1983; Reichardt, 1985; Miyazaki, 1993).

Mota (1976) verificou que as diferenças acentuadas de retenção de água entre os horizontes genéticos $\mathrm{A} e$ $B$ de um Alfissol eram devidas às diferenças entre os teores de argila dos horizontes. No mesmo trabalho, o autor encontrou alta dependência da água retida nas várias tensões com os percentuais de argila e silte dos horizontes.

Em solo cultivado por um período de 10 anos, submetido a diferentes sistemas de cultivo, Palmeira et al. (1999) observaram que a maior concentração de agregados estáveis em água na classe de maior diâmetro $(4,76 \mathrm{~mm})$ ocorreu nos sistemas de cultivo com mínima mobilização do solo, enquanto a maior concentração na menor classe de diâmetro $(0,105 \mathrm{~mm})$ ocorreu nos tratamentos com maior ação antrópica.

Assim, o trabalho objetivou caracterizar os principais solos explorados com a cultura do melão no Rio Grande do Norte, no tocante aos aspectos físicos, visando fornecer subsídios para adequado manejo da cultura e do solo.

\section{MATERIAL E MÉTODOS}

\section{Descrição da região de estudo}

O trabalho foi desenvolvido no pólo agrícola da região de Mossoró, oeste do Estado do Rio Grande do Norte, na Chapada do Apodi, em setembro de 2003, onde foram selecionadas três áreas com os principais solos representativos da região cultivados com melão. As áreas estudadas estão sobre calcário da Formação Jandaíra, que, em determinados locais, é recoberto por sedimentos arenosos mais recentes do Grupo Barreiras. Ocorrem também áreas aluvionais formadas por sedimentos não consolidados, arenosos, siltosos e argilosos referentes ao Holoceno (DNOCS, 1978).

A Formação Jandaíra é caracterizada por camadas de calcário calcítico de cor cinza-clara e branca ou amarela, com granulação fina a média, e por calcário dolomítico cinzento ou amarelo de granulação geralmente mais grosseira. Além destes, são encontrados outros tipos: calcário com pequenas conchas de moluscos, nodulosos, lageados, gredosos, arenosos e arenitos calcíferos. Por outro lado, o Grupo Barreiras é formado por sedimentos de areia, silte e argila de cores bastante variadas, sendo a vermelha a predominante.

De acordo com a classificação de Köppen, o clima predominante na região é do tipo BSw'h', caracterizado por ser muito quente e semi-árido, com a estação chuvosa se atrasando para o outono. Os índices pluviométricos situam-se, em média, em torno dos 
$677 \mathrm{~mm}$ por ano (Amaro Filho, 1991). Como a evaporação é sempre maior que a precipitação, as águas pluviais não são suficientes para formar mananciais perenes. A temperatura média anual é de $27,6{ }^{\circ} \mathrm{C}$ (Chagas, 1997; SERHID, 2001). Em geral, na região de estudo, predomina o relevo plano (DNOCS, 1978).

\section{Método de trabalho}

\section{Trabalhos de campo}

Após as áreas terem sido selecionadas, foram efetuadas observações de solos, vegetação e relevo. Em cada área foi aberta uma trincheira para descrição do perfil representativo (Perfil 1: S $5^{\circ} 04,882^{\prime}$ ' WO $37^{\circ} 41,717$ '; Perfil 2: S $4^{\circ} 52,929$ 'WO $37^{\circ} 26,808$ '; Perfil 3: S $5^{\circ} 3,646^{\prime}$ WO $37^{\circ} 24,005^{\prime}$ ), seguindo os critérios estabelecidos por Santos et al. (2005). A nomenclatura dos horizontes diagnósticos e a classificação taxonômica dos solos foram feitas de acordo com o Sistema Brasileiro de Classificação de Solos (Embrapa, 2006).

\section{Trabalhos de laboratório}

As amostras coletadas em cada perfil foram analisadas no Laboratório de Física do Solo, da Universidade Federal do Ceará (UFC), quanto às determinações pertinentes ao objetivo do estudo.

Foram determinados: granulometria e argila dispersa em água (método da pipeta) - as areias foram separadas em peneira de malha de $0,053 \mathrm{~mm}$ de diâmetro e fracionadas segundo a classificação granulométrica do Departamento de Agricultura dos Estados Unidos; densidade das partículas (método do balão volumétrico); densidade do solo (método do anel volumétrico); microporosidade (determinada em funil de Haines, mediante aplicação de tensão de $6 \mathrm{kPa}$ sobre as amostras); curva característica de umidade (tensões de 0, 2, 4, 6, 8 e 10, 33, 50, 100, 500 e $1.500 \mathrm{kPa})$ - o ajuste da curva foi feito pelo modelo matemático proposto por van Genuchten (1980); estabilidade de agregados (método de tamisação por via úmida) - o teor de agregados foi expresso em cinco classes de diâmetro: 4,00-2,00 mm, 2,00-1,00 mm, $1,00-0,50 \mathrm{~mm}, 0,50-0,25 \mathrm{~mm}$ e $<0,25 \mathrm{~mm}$ ); e limites de Atterberg (o limite de liquidez foi determinado pela percentagem de umidade correspondente a 25 pancadas no aparelho de Casagrande); o limite de plasticidade, pela percentagem de umidade na qual o solo, na forma de bastão, começou a se quebrar; e o limite de pegajosidade, pela percentagem de umidade na qual o solo se tornou aderente). As determinações foram feitas com três repetições e baseadas nos métodos adotados pela Embrapa (1997).

O grau de floculação, a porosidade total e a macroporosidade foram calculados pelas expressões GF $=[($ argila total - argila natural $) /$ argila total $] \times 100, \alpha$ $=[1-(\rho s o l o / \rho p a r t i ́ c u l a s) \times 100]$ e macroporosidade $=$ $\alpha$-microporosidade, respectivamente.

\section{RESULTADOS E DISCUSSÃO}

Com relação à granulometria (Quadro 1), observase que o perfil 1 (Cambissolo Háplico Ta eutrófico típico - CXve) apresenta distribuição vertical das frações granulométricas sem grandes variações, conferindo uma classe textural do tipo franco-argiloarenosa para todos os horizontes. O perfil 2 (Latossolo VermelhoAmarelo eutrófico típico - LVAe) apresenta distinção bem nítida entre as composições granulométricas dos dois horizontes superficiais e dos dois subjacentes, resultando na definição das classes texturais francoarenosa e franco-argiloarenosa para os dois horizontes mais superficiais e os dois mais profundos, respectivamente. Quanto ao perfil 3 (Argissolo Vermelho distrófico arênico - PVd), os teores de areia, em relação aos de silte e argila, são bastante elevados em todos os horizontes, definindo as classes texturais areia, areia franca e franco-arenosa no sentido superfície-profundidade.

A areia do perfil 1 (CXve) é constituída na sua essência por frações muito grossas, evidenciando que, em um tempo geológico relativamente curto, as ações do intemperismo foram insuficientes para promover desagregação mais acentuada sobre a referida fração. Por outro lado, as areias dos perfis 2 (LVAe) e 3 (PVd) estão constituídas predominantemente por frações classificadas como grossas, médias e finas, indicando, nestes casos, um processo de intemperismo bem mais acentuado em relação ao perfil 1 (CXve).

A fração silte do perfil 1(CXve), em contraste com os perfis 2 (LVAe) e 3 (PVd), apresenta valores bem mais elevados, corroborando a hipótese de que os dois últimos sofreram processo de intemperização mais intenso que o primeiro. Como os solos dos perfis 2 (LVAe) e 3 (PVd) têm como material de origem os sedimentos do Grupo Barreiras, é comum encontrar baixos teores de silte na composição granulométrica (Duarte et al., 2000; Romero, 2003).

Quanto à argila, a ausência de gradiente textural expressivo para o perfil 1 (CXve) é explicada pelo grau de intemperização a que este solo está submetido, uma vez que é um solo jovem; portanto, os fatores e processos de formação não atuaram de modo a provocar mudanças perceptíveis no tocante à diferenciação textural em profundidade. Por outro lado, os gradientes texturais bem expressivos nos perfis 2 (LVAe) e 3 (PVd), caracterizados pelo acúmulo de argila em profundidade, são, segundo Romero (2003), decorrentes dos processos isolados ou combinados de eluviação/iluviação, formação de argila in situ, erosão diferenciada e intemperização intensa com destruição dos filossilicatos das camadas superficiais.

No que se refere à argila dispersa em água (Quadro 1), apenas os horizontes superficiais dos perfis 1 (CXve) e 2 (LVAe) apresentaram valores relativamente elevados, refletindo em grau de floculação de apenas 55 e $56 \%$, respectivamente. Pela teoria do ponto isoelétrico, em que as cargas elétricas 
Quadro 1. Atributos físicos dos perfis estudados

\begin{tabular}{|c|c|c|c|c|c|c|c|c|c|c|c|c|c|c|c|c|c|c|c|}
\hline \multirow[b]{2}{*}{ Hor. } & \multirow[b]{2}{*}{ Prof. } & \multicolumn{6}{|c|}{$\operatorname{Areia}^{(1)}$} & \multirow[b]{2}{*}{ Silte } & \multirow{2}{*}{$\frac{\text { Argila }}{\text { Total Água }}$} & \multirow{2}{*}{$\begin{array}{c}\text { Classe } \\
\text { textural }^{(2)}\end{array}$} & \multirow{2}{*}{$\begin{array}{l}\text { Grau } \\
\text { de } \\
\text { Floc. }\end{array}$} & \multirow{2}{*}{$\begin{array}{l}\text { Relação } \\
\text { silte/arg. }\end{array}$} & \multirow{2}{*}{\multicolumn{2}{|c|}{$\frac{\text { Densidade }}{\text { Solo Part. }}$}} & \multirow{2}{*}{\multicolumn{2}{|c|}{$\frac{\text { Porosidade }}{\text { Macro Micro Total }}$}} & \multicolumn{3}{|c|}{ Limite } \\
\hline & & MG & G & M & $\mathbf{F}$ & MF & Total & & & & & & & & & & Liquidez & $\begin{array}{l}\text { Plasti- } \\
\text { cidade }\end{array}$ & $\begin{array}{c}\text { Pegajo- } \\
\text { sidade }\end{array}$ \\
\hline
\end{tabular}

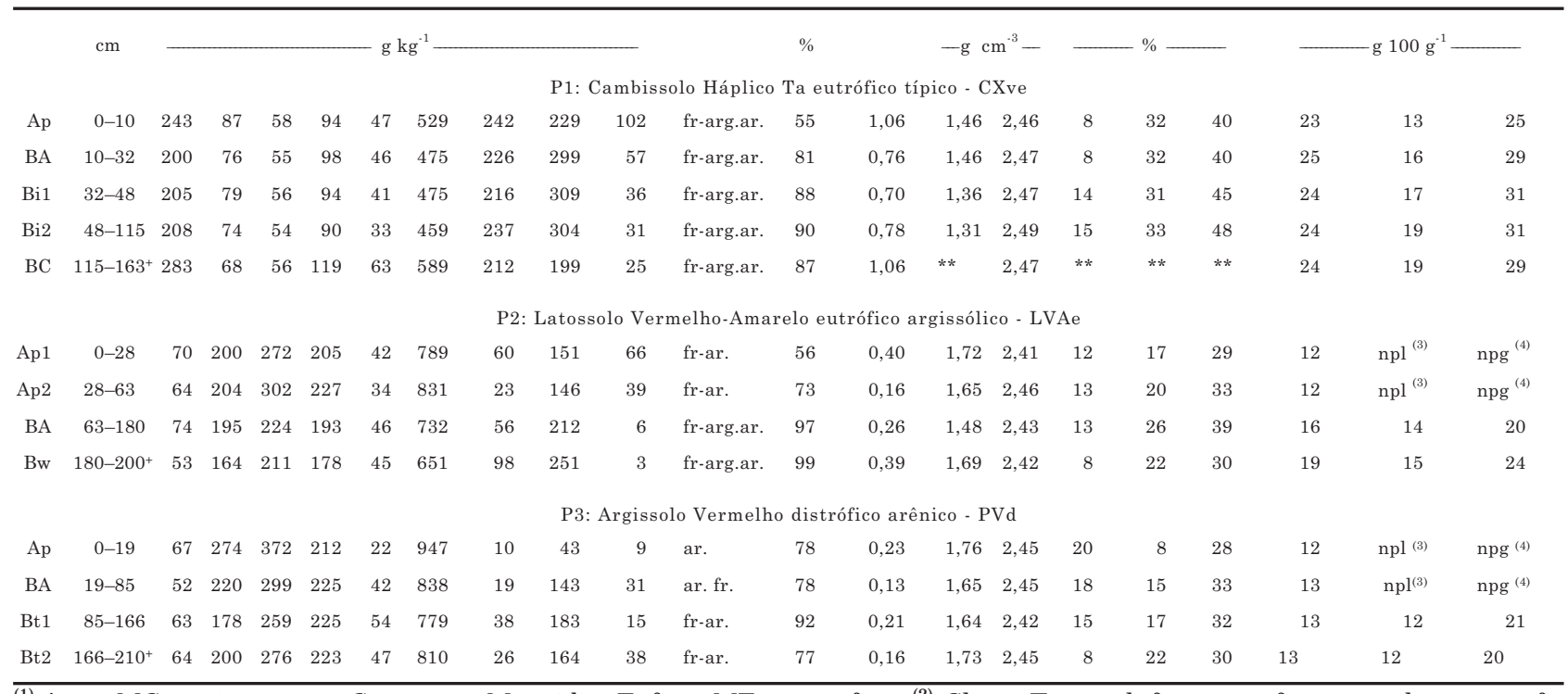

(1) Areia MG: muito grossa; G: grossa; M: média; F: fina; MF: muito fina. ${ }^{(2)}$ Classe Textural: fr-arg.ar.: franco-argiloarenosa; frar.: franco-arenosa; ar.: arenosa; ar. fr.: areia franca. ${ }^{(3)}$ não-plástico. ${ }^{(4)}$ não-pegajoso. **: não determinado.

do sistema estariam em equilíbrio e, portanto, a floculação seria máxima, são esperados resultados que exprimam determinado nível de dispersão dos colóides, uma vez que, no balanço de cargas para todos os horizontes dos perfis, há sempre um saldo de cargas negativas, implicando a dispersão das argilas (Rando, 1981; Corrêa et al., 2003).

Pedrotti et al. (2003), estudando alguns atributos físicos do solo, associaram o surgimento de cargas elétricas negativas no solo à matéria orgânica, observando correlação negativa significativa, ou seja, que aumentos no teor de matéria orgânica favoreciam a dispersão da fração argila. Entretanto, em se tratando dos resultados obtidos para os horizontes superficiais dos perfis supracitados, há uma hipótese complementar para melhor compreensão dos resultados. Notadamente, os perfis 1 (CXve) e 2 (LVAe) são muito mais trabalhados que o perfil 3 (PVd) no aspecto do uso de máquinas e implementos agrícolas (por exemplo, arados, grades). Logo, a ruptura dos agregados com redução à forma de grãos individualizados, aliada às questões das cargas elétricas, é também um dos fatores que predispõem à dispersão dos colóides.

Pela relação silte/argila, indicativa do estado de evolução dos solos (Embrapa, 2006; Mota et al., 2002), observou-se que a hipótese de que o perfil 1 (CXve) é menos evoluído que os perfis 2 (LVAe) e 3 (PVd) foi corroborada, uma vez que os valores da relação para o primeiro perfil foram bem superiores aos dos dois últimos.
Em se tratando da densidade do solo (Quadro 1), observou-se, em todos os perfis, que os valores se encontram bem acima dos normalmente estabelecidos como ideais, exceto nos horizontes $\mathrm{Bi} 1$ e $\mathrm{Bi} 2$ do Cambissolo (USDA, 1999), para as distintas classes texturais de solos, notadamente nas camadas mais superficiais, dificultando inclusive, em observações visuais feitas no campo, a germinação de sementes e penetração do sistema radicular em profundidade, sobretudo no perfil 2 (LVAe).

Esses resultados são devidos, provavelmente, ao elevado grau de dispersão de argila nesses horizontes, provocado pelo uso intensivo de máquinas e implementos agrícolas, o que favorece um rearranjamento desses minerais, que se deslocam a curta distância e preenchem os espaços vazios do solo, aumentando a densidade, ocasionando a compactação. Por outro lado, os elevados valores de densidade do solo encontrados em subsuperfície são resultantes de processos de migração de argila, e até silte, dos horizontes superficiais, principalmente por neoformação de argila in situ, evidenciando o fenômeno conhecido na literatura por adensamento (Moniz, 1996).

Independentemente do processo que deu origem ao aumento da densidade do solo, Alencar (2000) constatou, em coletas de solo e descrições no campo, que em áreas cultivadas com melão na Chapada do Apodi, as quais apresentavam problemas com densidades do solo elevadas, as raízes eram poucas e finas nos horizontes superficiais e poucas ou raras 
nos subsuperficiais, o que resultava sempre em perdas na produtividade da cultura.

Quanto aos valores de densidade de partículas, verificou-se que todos os horizontes dos perfis estão abaixo do valor universal geralmente usado, $2,65 \mathrm{~g} \mathrm{~cm}^{-3}$ (considerando que na maioria dos solos o quartzo predomina em relação aos outros minerais), indicando a existência de partículas menos densas que o quartzo, que influenciam o valor médio para abaixo do valor médio universal.

Os dados referentes à porosidade total (Quadro 1) indicam que o perfil 1 (CXve) apresenta valores geralmente aceitos para solos cuja textura é semelhante à que este perfil apresenta, já que são comuns para solos de textura média a argilosa valores da ordem de 40 a $60 \%$ (Kiehl, 1979). Para os perfis 2 (LVAe) e 3 (PVd), os valores encontram-se abaixo dos limites geralmente estabelecidos para classes texturais semelhantes, isto é, de 35 a $50 \%$.

Uma avaliação vertical sobre o comportamento da porosidade total revela que, principalmente nos perfis 1 e 2, ela aumenta com a profundidade, contrariando informações encontradas na literatura (Assis Júnior, 1999). E que na superfície do solo espera-se maior conteúdo de matéria orgânica, contribuindo para aumento da porosidade total. Como as condições naturais da região não são favoráveis ao acúmulo de matéria orgânica na superfície e os agricultores não têm a tradição de adotar sistemas de manejo que visem o aporte de resíduos orgânicos ao sistema e, ainda, há o uso indiscriminado de maquinaria pesada sobre o solo, os processos induzem à compactação, com reflexos diretos na redução da porosidade total, notadamente na macroporosidade.

A distribuição da porosidade em macro e microporosidade, tornando ampla a visão sobre o comportamento dos três perfis em relação aos processos de condução e armazenamento de água e difusão de gases, evidenciou que o perfil 1 (CXve) apresenta desbalanço entre as proporções, com sérias limitações à entrada e circulação de água e ar nas camadas superiores, visto que apresenta relação macro:microporos de 1:4 nos primeiros $48 \mathrm{~cm}$ de profundidade, correspondentes ao sistema radicular efetivo da cultura do meloeiro; por outro lado, apresenta capacidade de armazenamento de água boa, mas, se não manejada corretamente, poderá causar deficiência de oxigenação das raízes. Quanto ao perfil 2 (LVAe), apesar de os valores de porosidade total serem baixos, há distribuição proporcional relativamente boa entre as duas classes de poros (1:1,4 e 1:1,5 nos dois primeiros horizontes, respectivamente). No perfil 3 (PVd) constatou-se o inverso do perfil 1, ou seja, aumento na proporção de macroporos em detrimento da microporosidade $-2,5: 1$ nos primeiros $20 \mathrm{~cm}$ de solo -, dificultando sobremodo o suprimento de água às culturas, exigindo manejo de irrigação bem diferente daquele dos perfis anteriores.
Considerando que as raízes da maioria das culturas podem crescer com macroporosidade acima de $10 \%$ (Kiehl, 1979; Klein \& Libardi, 2002) e que o conteúdo de água armazenada deve ser maior que o de ar, o solo ideal é aquele que apresenta proporção de macro:microporos de 1:2, garantindo suficiente aeração, permeabilidade e armazenamento de água.

Em termos de consistência, é imprescindível o conhecimento das implicações de ordem prática quando não são definidas faixas ótimas de umidade em que os solos devem ser trabalhados, sem que suas estruturas sejam modificadas a ponto de prejudicar o desenvolvimento das culturas. É que com o emprego de máquinas e implementos agrícolas no preparo do solo, tratos culturais, colheitas, por exemplo, ocorrem interações entre as máquinas-implementos com o solo, caracterizadas pela aplicação de forças e reação resultante. Posto isso, a definição de um ponto ótimo de umidade para distribuição dessas forças no solo é de grande importância para minimizar o impacto das máquinas e veículos sobre as mais distintas propriedades dinâmicas do solo e crescimento das culturas. Além disso, as operações em faixas ótimas de umidade do solo requerem potência mínima por parte dos motores agrícolas, aumentando, portanto, a vida útil destes.

Desse modo, para trabalhar com compressão e compactação mínimas, é necessário que os solos sejam trabalhados com maquinaria e implementos somente em umidade abaixo do limite de plasticidade, no estado friável (Kiehl, 1979; Rando, 1981). O perfil 1 (CXve), por apresentar conteúdo de argila relativamente significativo em todos os horizontes, evidencia as três formas de consistência bastante nítidas, ou seja, a faixa de plasticidade, definida pelos limites de liquidez e plasticidade, é bastante ampla. Já os horizontes superficiais dos perfis 2 (LVAe) e 3 (PVd), por não exibirem plasticidade e pegajosidade, atingem a friabilidade com conteúdos relativamente baixos de água. Apresentam a vantagem de poderem ser trabalhados mecanicamente em ampla faixa de umidade, exceto nos estados de fluidez e tenacidade.

Com base no índice de plasticidade, sugerido por Caputo (1973), em que valor < 1 - solo não apresenta plasticidade; valor de 1 até 7 - fracamente plástico; valor $>7$ até 15 - medianamente plástico; e valor acima de 15 - altamente plástico, os dois horizontes superficiais do perfil 1 (CXve) são considerados como medianamente plásticos, e os três mais profundos, como fracamente plásticos. Quanto aos perfis 2 (LVAe) e $3(\mathrm{PVd})$, os dois horizontes superficiais não apresentam plasticidade, enquanto os dois mais profundos são fracamente plásticos.

Verificou-se que no perfil 1 (CXve) a maior concentração de agregados estáveis ocorreu na classe de diâmetro com limites de 4,76-2,00 mm (Quadro 2). Em se tratando de uma avaliação no sentido vertical, constatou-se, com exceção dos horizontes Bi1 e Bi2, que a estabilidade aumentou com a profundidade, fato 
Quadro 2. Estabilidade de agregados em água dos perfis estudados

\begin{tabular}{|c|c|c|c|c|c|c|c|}
\hline \multirow{2}{*}{ Horizonte } & \multirow{2}{*}{ Profundidade } & \multicolumn{5}{|c|}{ Classe de agregado $(\varnothing \mathrm{em} \mathrm{mm})$} & \multirow{2}{*}{$\operatorname{DMP}^{(1}$} \\
\hline & & $4,76-2,00$ & $2,00-1,00$ & $1,00-0,50$ & $0,50-0,25$ & $<0,25$ & \\
\hline \multicolumn{7}{|c|}{$\mathrm{cm}$} & \multirow[t]{2}{*}{$\mathrm{mm}$} \\
\hline & \multicolumn{6}{|c|}{ P1: Cambissolo Háplico Ta eutrófico típico - Cxve } & \\
\hline Ap & $0-10$ & 476,3 & 193,0 & 114,5 & 61,6 & 154,7 & 2,0 \\
\hline $\mathrm{BA}$ & $10-32$ & 624,8 & 214,7 & 64,6 & 35,9 & 60,1 & 2,5 \\
\hline Bi1 & $32-48$ & 394,3 & 246,7 & 125,3 & 66,7 & 166,9 & 1,8 \\
\hline $\mathrm{Bi} 2$ & $48-115$ & 502,7 & 226,1 & 86,1 & 47,8 & 137,3 & 2,1 \\
\hline \multirow[t]{2}{*}{$\mathrm{BC}$} & $115-163^{+}$ & 757,9 & 107,1 & 30,9 & 22,1 & 81,9 & 2,8 \\
\hline & \multicolumn{7}{|c|}{ P2: Latossolo Vermelho-Amarelo eutrófico argissólico - LVAe } \\
\hline Ap 1 & $0-28$ & 124,2 & 229,8 & 195,5 & 113,0 & 337,5 & 1,0 \\
\hline Ap2 & $28-63$ & 347,4 & 165,5 & 112,2 & 73,3 & 301,6 & 1,6 \\
\hline $\mathrm{BA}$ & $63-180$ & 435,0 & 220,1 & 80,9 & 45,6 & 218,4 & 1,9 \\
\hline \multirow[t]{2}{*}{$\mathrm{Bw}$} & $180-200^{+}$ & 599,9 & 172,7 & 69,0 & 27,8 & 130,7 & 2,4 \\
\hline & \multicolumn{7}{|c|}{ P3: Argissolo Vermelho distrófico arênico - PVd } \\
\hline Ap & $0-19$ & 417,7 & 245,4 & 64,3 & 43,1 & 229,4 & 1,9 \\
\hline BA & $19-85$ & 783,7 & 104,8 & 20,9 & 19,7 & 70,8 & 2,8 \\
\hline Bt1 & $85-166$ & * & 660,0 & 187,3 & 25,9 & 126,8 & 1,2 \\
\hline Bt2 & $166-210^{+}$ & $*$ & 654,2 & 162,5 & 35,7 & 147,6 & 1,1 \\
\hline
\end{tabular}

confirmado pelos valores dos diâmetros médios ponderados. Do ponto de vista edáfico, é primordial que os agregados do solo sejam estáveis nas maiores classes de diâmetro, garantindo, assim, boa difusão de gases e condução de água no solo e, por outro lado, maior resistência à erosão.

O fato de a estabilidade aumentar com a profundidade é perfeitamente coerente, pelas seguintes razões: o teor de matéria orgânica, eficiente agente cimentante (Paladini \& Mielniczuk, 1991; Assis Júnior, 1999), é baixo; em que pesem os horizontes apresentarem a mesma classe textural, os teores de areia são bem mais elevados em superfície, provocando efeitos, segundo Reichert et al. (1993), negativos na gênese e estabilização dos agregados; por último, o uso de implementos tende a destruir os agregados na camada agricultável do solo.

Quanto ao perfil 2 (LVAe), identificou-se que na camada superficial há concentração muito elevada de agregados pequenos, resultantes - presume-se, já que não há nenhuma característica especial que o diferencie dos outros horizontes - da ação antrópica pelo uso indiscriminado de implementos agrícolas (Palmeira et al., 1999). Saliente-se que o uso de implementos agrícolas nas operações nem sempre se traduz em destruição de características desejáveis ao solo. O problema é que, na maioria das vezes, as operações são realizadas sem a preocupação de atender aos limites ótimos de umidade estabelecidos para tal, discutidos anteriormente. Em profundidade, os resultados encontrados indicaram concentração bastante razoável de agregados na classe de maior diâmetro estudada, confirmando o raciocínio desenvolvido anteriormente.

O perfil 3 (PVd), bem menos trabalhado que os outros dois, apresentou em superfície percentual considerável de agregados estáveis em classes de tamanhos maiores. Por outro lado, em profundidade, diferentemente dos outros perfis estudados, não foi possível sequer obter agregados secos ao ar com diâmetro maior que $4,76 \mathrm{~mm}$, isto é, há formação de agregados grandes, mas estes esboroam com tanta facilidade que não resistem ao transporte e manuseio, fato que pode ser explicado pela teoria clássica da gênese de agregados. Segundo a teoria, os agregados formam-se somente com partículas de elevada CTC e grande área superficial, e a resistência deles depende da natureza dos cátions trocáveis. Pelo exposto, fica evidente o porquê de não se obterem agregados de maior tamanho, dados os baixos conteúdos de argila (conseqüentemente, baixa área superficial das partículas) e a capacidade de troca verificados nos dois últimos horizontes do perfil analisado.

Em linhas gerais, não são conhecidos números absolutos para interpretação de propriedades físicas do solo com base nos resultados da análise de 
agregados. De acordo com Kiehl (1979), agregados com diâmetro médio ponderado acima de $0,5 \mathrm{~mm}$ são considerados relativamente resistentes ao esboroamento e dispersão e, dependendo do manejo, bons condutores de água e ar. Posto isso, todos os perfis estudados, seguindo o critério desse autor e resguardadas as peculiaridades e os comentários feitos para cada um, apresentam bons índices de agregação.

Uma breve visualização dos dados de diâmetro médio ponderado permite uma inferência importante: que a forma de uso da camada arável do solo, no atual sistema de manejo convencional, está provocando redução no tamanho dos agregados estáveis, uma vez que em superfície os agregados são menores que em profundidade, exceto no perfil 3 , por razões já expostas.

Quanto à retenção de água em distintos potenciais mátricos, constatou-se que em todos os perfis há estreita relação entre os conteúdos de água adsorvida e os teores de argila (Quadro 1), isto é, à medida que aumentam os teores de argila, aumenta também a quantidade de água retida. Contrastando os três perfis entre si, verifica-se que o perfil 1 (CXve) apresenta conteúdo de água, em qualquer que seja o potencial mátrico, muito superior ao dos perfis 2 (LVAe) e 3 (PVd), o que sugere manejo de irrigação diferente daquele, em relação aos dois últimos. O perfil 2 (LVAe) apresenta retenção de água relativamente baixa, requerendo, portanto, cuidados especiais para suprimento de água às plantas. Quanto ao perfil $3(\mathrm{PVd})$, há uma situação mais adversa, já que os conteúdos de água retidos são extremamente baixos. Pelos dados observados, esse solo requer suprimento de água praticamente contínuo e com uso de sistema de irrigação altamente eficiente. Uma das maneiras de melhorar a retenção de água por este solo é a incorporação de resíduos orgânicos, embora os efeitos só possam ser sentidos a longo prazo (Negreiros et al., 2001), bem como o uso de cobertura morta como forma de reduzir as perdas de água para a atmosfera (Reichardt, 1990).

No perfil 1 (CXve) (Figura 1) pode-se observar que as curvas em todos os horizontes são muito semelhantes e praticamente se sobrepõem, especialmente para os horizontes Ap e BA, confirmando o que já foi discutido (Quadro 1), ou seja, que este solo é bastante uniforme em relação à distribuição das frações granulométricas, tanto é que fora classificado como franco-argiloarenoso em todos os horizontes. Saliente-se que não é regra geral horizontes de mesma classe textural apresentarem curvas semelhantes, pois existem outros aspectos que interferem no comportamento das curvas. Como a granulometria correlaciona-se muito bem com a retenção de água (Buckman \& Brady, 1989; Thurler, 1989), fica evidente o motivo de as curvas terem praticamente o mesmo comportamento.

As curvas que representam o perfil 2 (LVAe) (Figura 2) mostram distinção mais nítida entre si, inclusive não só no conteúdo de água que representam, mas no formato delineado, evidenciando não haver retenção de água tão uniforme para uma mesma tensão quanto se observou para o perfil anterior. Em que pese a classificação textural para os horizontes Ap1 e Ap2 ter sido franco-arenosa, e para os horizontes BA e $\mathrm{Bw}$, franco-argiloarenosa, fica claro que em uma mesma classe textural solos ou camadas destes podem reter água com maior ou menor intensidade em uma mesma tensão, dependendo do teor e do tipo de argila dominante. O fato de solos de mesma classe textural reterem diferentes conteúdos de água em uma mesma tensão deve-se, em parte, à ampla variação nos teores das frações granulométricas que uma classe pode abranger e também às variações na densidade do solo (Kiehl, 1979; Reichardt, 1990).

Para o perfil 3 (PVd) (Figura 3) a curva do horizonte Ap é a que mais se distancia das outras em termos de retenção de água para uma mesma tensão. Inclusive, como se pode constatar, a área que está sob a referida curva é bem menor em comparação às outras três do mesmo perfil. É importante notar também que este solo, em todos os horizontes, só consegue reter quantidade de água considerável em potenciais muito baixos.

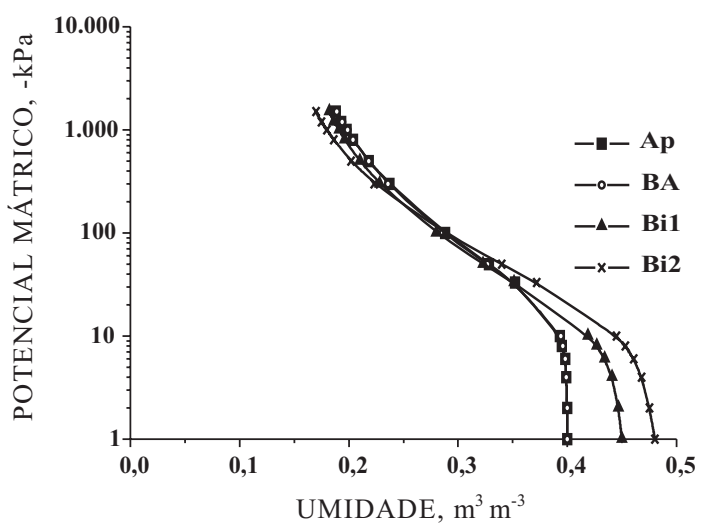

Figura 1. Curvas características de umidade do Cambissolo Háplico Ta eutrófico típico.

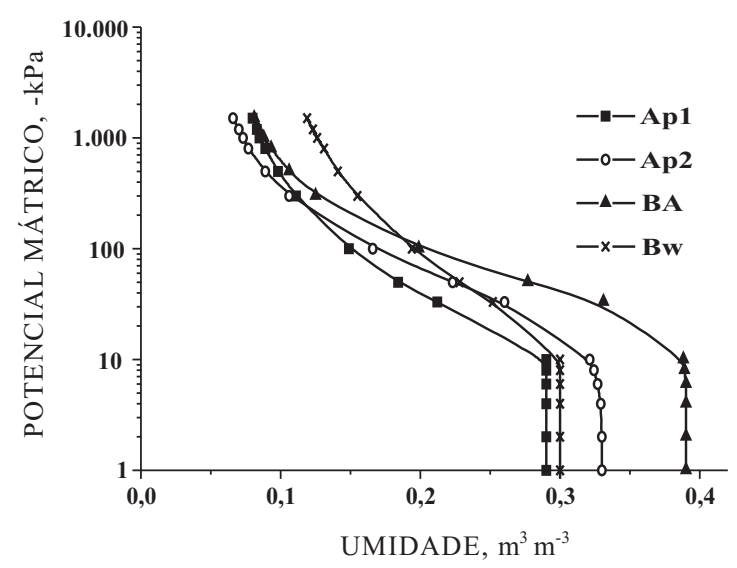

Figura 2. Curvas características de umidade do Latossolo Vermelho-Amarelo eutrófico típico. 


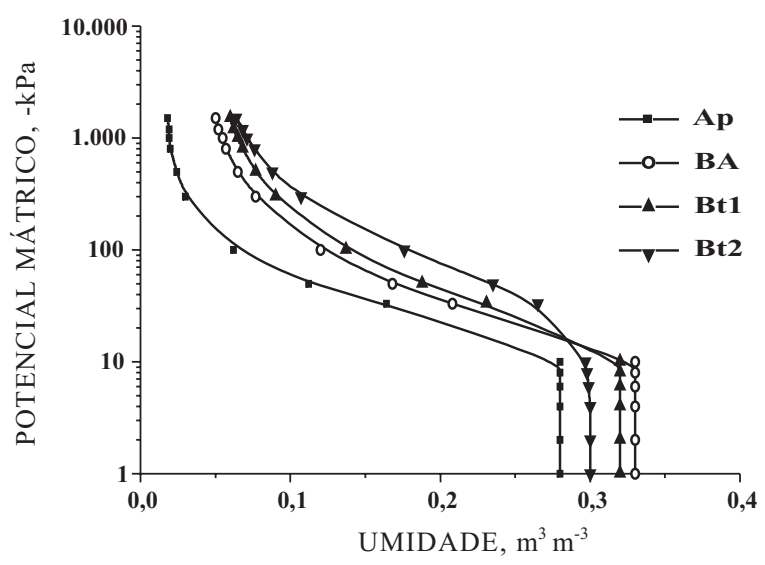

Figura 3. Curvas características de umidade do Argissolo Vermelho distrófico arênico.

\section{CONCLUSÕES}

1. Os perfis apresentam densidade acima dos valores normais para solos afins, com maiores agravantes para os perfis 2 (LVAe) e 3 (PVd), que se refletem na porosidade total e no desbalanço da proporção macro:microporosidade.

2. O manejo da irrigação dos três solos deve ser diferenciado, obedecendo às relações macro: microporosidade.

3. A estabilidade de agregados em água é relativamente boa em todos os perfis.

4. A capacidade de água disponível para a profundidade de $30 \mathrm{~cm}$ (profundidade efetiva para as raízes do meloeiro) é decrescente do perfil 1 (CXve) para o perfil $3(\mathrm{PVd})$.

5. O uso e manejo do solo diminuíram o grau de floculação dos horizontes superficiais dos perfis 1 (CXve) e 2 (LVAe).

6. Considerando o índice de plasticidade, o risco de degradação pelo uso de máquinas e implementos é acentuado no perfil 1 (CXve) e baixo nos perfis 2 (LVAe) e 3 (PVd).

\section{LITERATURA CITADA}

ALENCAR, G.V. Compactação e, ou, adensamento de solos cultivados com melão em litosseqüência na região da Chapada do Apodi - RN. Fortaleza, Universidade Federal do Ceará, 2000. 75p. (Tese de Mestrado)

AMARO FILHO, J. Contribución al estudio del clima del Rio Grande do Norte. Madrid, ETSIA/UPM, 1991. 311p. (Tese de Doutorado)

ASSIS JÚNIOR, R.N. Física do solo. Fortaleza, Universidade Federal do Ceará, 1999. 52p. (Apostila)
BAVER, L.D. \& FARNSWORTH, R.B. Soil structure effects on the growth of sugar beets. Soil Sci. Am. Proc., 5:45-48, 1940.

BUCKMAN, H.O. \& BRADY, N.C. Natureza e propriedade dos solos. 7.ed. Tradução de A. B. de Figueiredo Filho. Rio de Janeiro, Freitas Bastos, 1989. 594p.

CAPUTO, H.P. Mecânica dos solos e suas aplicações. 3.ed. Rio de Janeiro, Livros Técnicos e Científicos, 1973. v.1. 1973. $242 \mathrm{p}$.

CHAGAS, F.C. Normais climatológicas para Mossoró-RN (1970-1996). Mossoró, Escola Superior de Agricultura de Mossoró, 1997. 40p. (Monografia de Graduação)

CORRÊA, M.M.; KER, J.C.; MENDONÇA, E.S.; RUIZ, H.A. \& BASTOS, R.S. Atributos físicos, químicos e mineralógicos de solos da região das várzeas de Sousa (PB). R. Bras. Ci. Solo, 27:311-324, 2003.

CORRECHEL, V. Densidade do solo: Influência da posição relativa à linha de plantio em dois sistemas de preparo do solo. Piracicaba, Escola Superior de Agricultura Luiz de Queiroz, 1998. 35p. (Tese de Mestrado)

DNOCS. Plano diretor para o aproveitamento dos recursos de solo e água do Vale do Apodi - Rio Grande do Norte. São Paulo, Hidroservice/Ministério do Interior/DNOCS ( $3^{\text {a }}$ Diretoria Regional), 1978. v. I. Tomo 1.

DUARTE, M.N.; CURI, N.; PÉREZ, D.V.; KÄMPF, N. \& CLAESSEN, M.E.C. Mineralogia, química e micromorfologia de solos de uma microbacia nos tabuleiros costeiros do Espírito Santo. Pesq. Agropec. Bras., 35:1237$1250,2000$.

EMPRESA BRASILEIRA DE PESQUISA AGROPECUÁRIA - EMBRAPA. Centro Nacional de Pesquisas de Solos. Sistema brasileiro de classificação de solos. 2.ed. Rio de Janeiro, Embrapa Solos, Brasília, Sistema de Produção de Informação, 2006. 306p.

EMPRESA BRASILEIRA DE PESQUISA AGROPECUÁRIA EMBRAPA. Manual de métodos de análise de solo. Rio de Janeiro, Centro Nacional de Pesquisa de Solos, 1997. 212p.

JACOMINE, P.K.T.; SILVA, F.B.R.; FORMIGA, R.A.; ALMEIDA, J.C.; BELTRÃO, V.A.; PESSOA, S.C.P. \& FERREIRA, R.C. Levantamento exploratório Reconhecimento de solos do Estado do Rio Grande do Norte. Recife, DPP/DA. Convênio MA/DNPEA/SUDENE/ DRN, MA/CONTAP/USAID/BRASIL, 1971. 531p. (Boletim Técnico, 21)

JORGE, J.A. Influência da subsolagem e gradagem do solo na dinâmica da água no perfil. Piracicaba, Escola Superior de Agricultura Luiz de Queiroz, 1983. 64p. (Tese de Doutorado)

KIEHL, E.J. Manual de edafologia: Relação solo-planta. Piracicaba, Ceres, 1979. 262p.

KLEIN, V.A. \& LIBARDI, P.L. Densidade e distribuição do diâmetro dos poros de um Latossolo Vermelho, sob diferentes sistemas de uso e manejo. R. Bras. Ci. Solo, $26: 857-867,2002$. 
MIYAZAKI, T. Water flow in soils. New York, Marcel Dekker, 1993. $296 \mathrm{p}$

MONIZ, A.C. Evolução de conceitos no estudo da gênese de solos. R. Bras. Ci. Solo, 20:349-362, 1996.

MOTA, F.O.B. Retenção de água em um perfil Alfissol do município de Mossoró - RN. Piracicaba, Escola Superior de Agricultura Luiz de Queiroz, 1976. 70p. (Tese de Mestrado)

MOTA, F.O.B.; OLIVEIRA, J.B. \& GEBHARDT, H. Mineralogia de um Argissolo Vermelho-Amarelo eutrófico e de um Planossolo Háplico eutrófico solódico numa toposseqüência de gnaisse no sertão central do Ceará. R. Bras. Ci. Solo, 26:607-618, 2002.

NEGREIROS, R.F.D.; MOTA, J.C.A. \& AMARO FILHO, J. Efeito da adição de compostos orgânicos na retenção de umidade em areias quartzosas. In: REUNIÃO ANUAL DA SOCIEDADE BRASILEIRA PARA O PROGRESSO DA CIÊNCIA, 53., Salvador, 2001. Anais/Resumos. Salvador, 2001. CD-ROM.

PALADINI, F.L.S. \& MIELNICZUK, J. Distribuição do tamanho de agregados de um solo Podzólico Vermelho-Escuro afetado por sistema de culturas. R. Bras. Ci. Solo, 15:135$140,1991$.

PALMEIRA, P.R.T.; PAULETTO, E.A.; GOMES, A.S. \& SILVA, J.B. Agregação de um Planossolo submetido a diferentes sistemas de cultivo. R. Bras. Ci. Solo, 23:189-195, 1999.

PEDROTTI, A.; FERREIRA, M.M.; CURI, N.; SILVA, M.L.N.; LIMA, J.M. \& CARVALHO, R. Relação entre atributos físicos, mineralogia da fração argila e formas de alumínio no solo. R. Bras. Ci. Solo, 27:1-9, 2003.

RANDO, E.M. Alterações nas características e propriedades físicas de um Latossolo Roxo distrófico, ocasionadas pelo cultivo convencional. Lavras, Escola Superior de Agricultura de Lavras, 1981. 161p. (Tese de Mestrado)
REICHARDT, K. A água em sistemas agrícolas. São Paulo, Manole, 1990. 188p.

REICHARDT, K. Processos de transferência no sistema soloplanta-atmosfera. 4.ed. São Paulo, Fundação Cargill, 1985. $445 p$.

REICHERT, J.M.; VEIGA, M. \& CABEDA, M.S.V. Índices de estabilidade de agregados e suas relações com características e parâmetros do solo. R. Bras. Ci. Solo, 17:283-290, 1993.

ROBINSON, F.E. Required per cent air space for normal growth of sugar cane. Soil Sci., 98:206-207, 1964.

ROMERO, R.E. Gênese e degradação de duripãs em uma toposseqüência dos tabuleiros costeiros, Conde - BA. Piracicaba, Escola Superior de Agricultura Luiz de Queiroz, 2003. 144p. (Tese de Doutorado)

SANTOS, R.D.; LEMOS, R.C.; SANTOS, H.G.; KER, J.C. \& ANJOS, L.H.C. Manual de descrição e coleta de solo no campo. 5. ed. Viçosa, MG, Sociedade Brasileira de Ciência do Solo, 2005. 100p.

SERHID. Bacia 01 - Apodi-Mossoró. Disponível em: <http:// www.serhid.rn.gov.br//detalhe.asp?Id

THURLER, A.M. Estimativa da macro e da microporosidade através da granulometria e densidades de partículas e do solo. Piracicaba, Escola Superior de Agricultura Luiz de Queiroz, 1989. 66p. (Tese de Mestrado)

USDA. Natural Resources Conservation Service. Soil quality test kit guide. Washington, 1999. 82p.

van GENUCHTEN, M.TH. A closed-form equation for predicting the conductivity of unsaturated soils. Soil Sci. Soc. Am. J., 44:892-897, 1980.

VIEIRA, L.S. Manual de ciência do solo com ênfase aos solos tropicais. 2.ed. São Paulo, Agronômica Ceres, 1988. 463p. 